\title{
Review Article \\ Recognition of Immune Response for the Early Diagnosis and Treatment of Osteoarthritis
}

\author{
Adrese M. Kandahari, ${ }^{1}$ Xinlin Yang, ${ }^{1}$ Abhijit S. Dighe, ${ }^{1}$ Dongfeng Pan, ${ }^{2}$ and Quanjun Cui ${ }^{1}$ \\ ${ }^{1}$ Department of Orthopaedic Surgery, University of Virginia School of Medicine, Charlottesville, VA 22908, USA \\ ${ }^{2}$ Department of Radiology and Medical Imaging, University of Virginia, Charlottesville, VA 22908, USA
}

Correspondence should be addressed to Quanjun Cui; qc4q@virginia.edu

Received 17 October 2014; Accepted 2 December 2014

Academic Editor: Patrizia D’Amelio

Copyright (C) 2015 Adrese M. Kandahari et al. This is an open access article distributed under the Creative Commons Attribution License, which permits unrestricted use, distribution, and reproduction in any medium, provided the original work is properly cited.

\begin{abstract}
Osteoarthritis is a common and debilitating joint disease that affects up to 30 million Americans, leading to significant disability, reduction in quality of life, and costing the United States tens of billions of dollars annually. Classically, osteoarthritis has been characterized as a degenerative, wear-and-tear disease, but recent research has identified it as an immunopathological disease on a spectrum between healthy condition and rheumatoid arthritis. A systematic literature review demonstrates that the disease pathogenesis is driven by an early innate immune response which progressively catalyzes degenerative changes that ultimately lead to an altered joint microenvironment. It is feasible to detect this infiltration of cells in the early, and presumably asymptomatic, phase of the disease through noninvasive imaging techniques. This screening can serve to aid clinicians in potentially identifying high-risk patients, hopefully leading to early effective management, vast improvements in quality of life, and significant reductions in disability, morbidity, and cost related to osteoarthritis. Although the diagnosis and treatment of osteoarthritis routinely utilize both invasive and non-invasive strategies, imaging techniques specific to inflammatory cells are not commonly employed for these purposes. This review discusses this paradigm and aims to shift the focus of future osteoarthritis-related research towards early diagnosis of the disease process.
\end{abstract}

\section{Introduction}

Osteoarthritis $(\mathrm{OA})$ is a painful and debilitative joint disease that commonly affects the hand, hip, and knee joints of aging adults. Disease progression is a leading cause of hospitalization and ultimately requires joint replacement surgery which costs the US healthcare industry over $\$ 42$ billion in 2009 for the hip and knee joints alone [1]. Clinical OA affects up to 30 million Americans including one-third of seniors aged 65 or older and $13.9 \%$ of all adults at least 25 years of age [2]. While disease-modifying antirheumatic drugs (DMARDs) have been identified for rheumatoid arthritis (RA), an inflammatory joint disease often studied and characterized in comparison with OA, similar therapy for OA has yet to be identified $[3,4]$. The classical definition of $\mathrm{OA}$ as a wear-andtear, noninflammatory disease has recently transitioned to an inflammatory disease lying on a spectrum between normal control and RA. Despite the fact that the immune system plays a significant role in both diseases, DMARDs effective in the treatment of RA, including tumor necrosis factor $\alpha$ (TNF $\alpha$ ) and interleukin-1 (IL-1) inhibitors, have so far proven unsuccessful in slowing disease progression and clinical deterioration of OA patients. This paper will characterize the key players in OA pathogenesis and identify diseasemodifying therapeutic strategies which could be reasonably accommodated in the setting of a prevalent, high-morbidity, and costly disease in the United States of America.

Recent research has established that multiple cells, cytokines, chemokines, complement, and other aspects of the immune system are involved in the pathogenesis of OA, with the roles of integral cells and proteins summarized in Tables 1 and 2, respectively. There exists a continuum of inflammation along the spectrum of normal, OA, and RA, with progressive increases in cytokines and other mediators of inflammation along with leukocyte infiltration [5]. OA pathogenesis is multifactorial and complex with evidence pointing towards unique phenotypes and seemingly discrete stages: early, intermediate, and late. Numerous pathways exist 


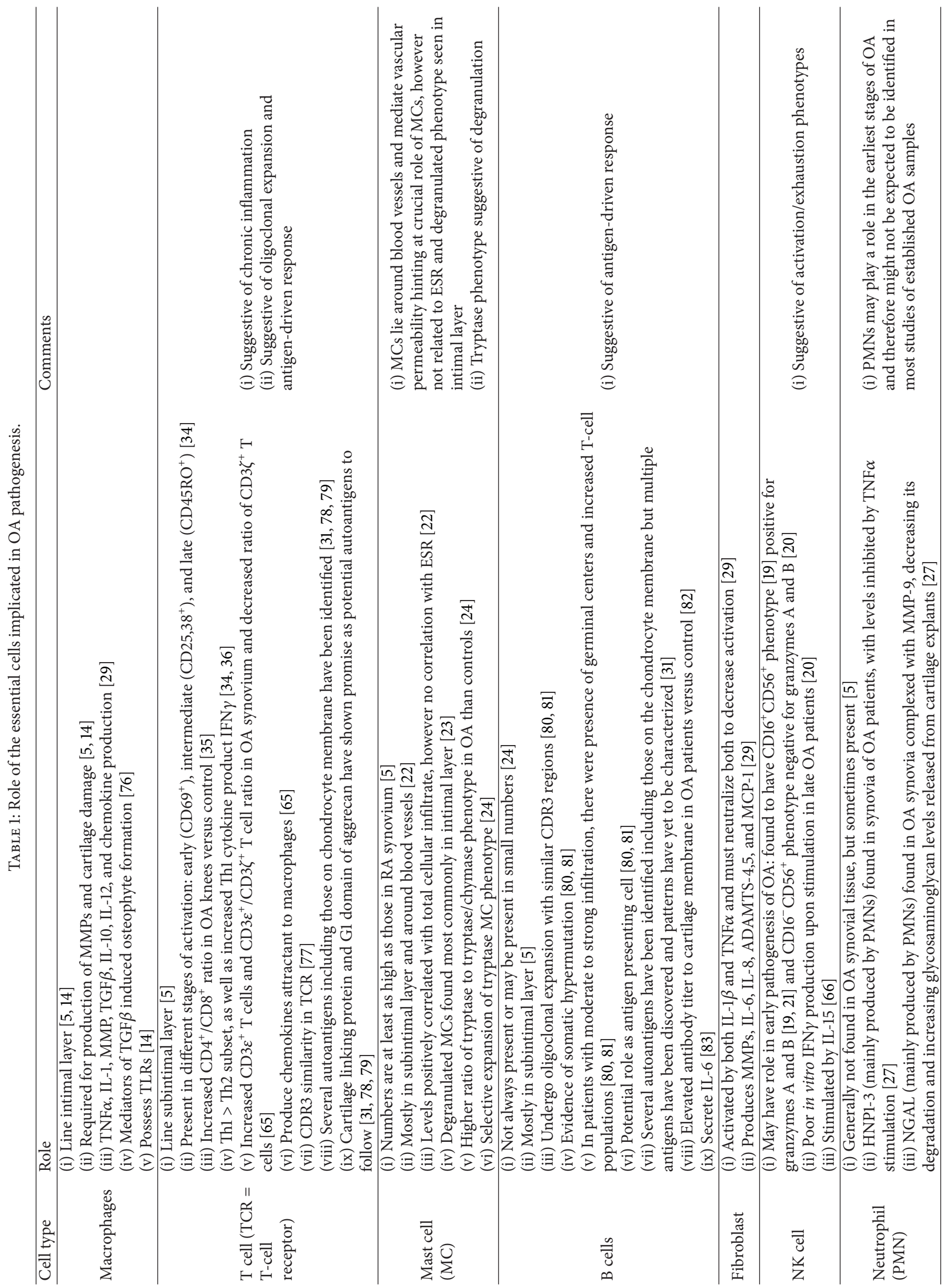




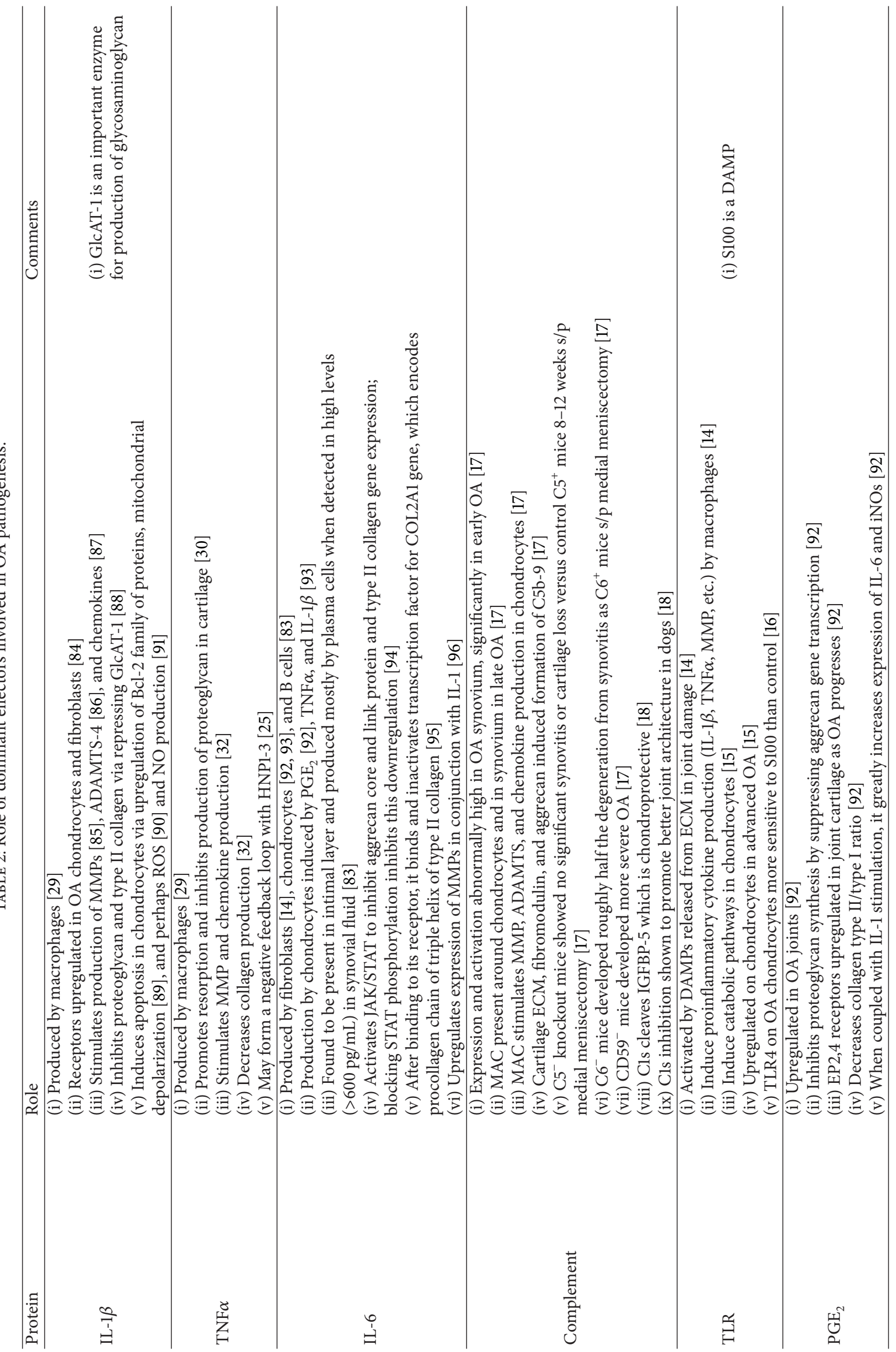




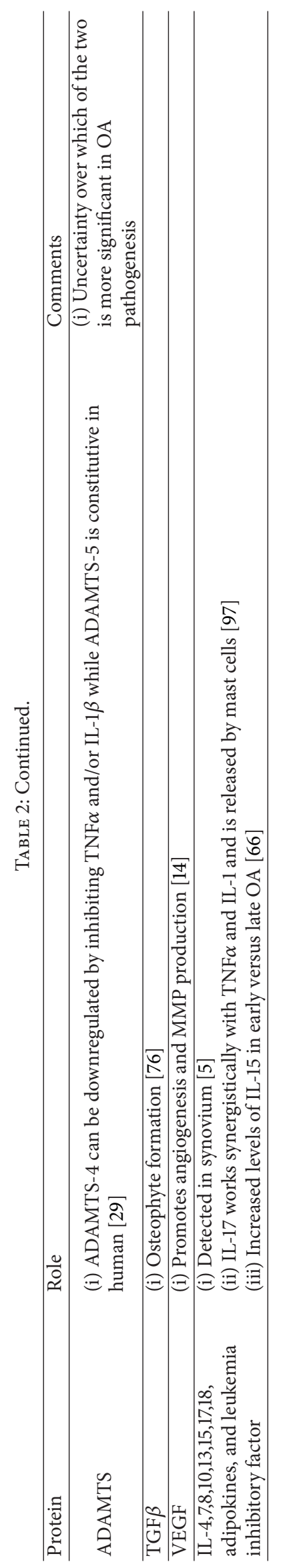


and not all may be implicated in specific joints or individuals, but all eventually lead to the endpoint of joint degeneration.

\section{Immune Response}

2.1. Early Innate Response. Both the innate and adaptive immune systems have been implicated in OA pathogenesis, but of particular interest is the role of the innate immune system in early OA. Pathogenesis begins with trauma to the joint, which may constitute repetitive microtrauma accumulated throughout a lifetime or a major traumatic event such as articular fracture. Trauma to the joint is absorbed by subchondral bone [6] and joint-associated fat pads [7], respectively. Subchondral bone releases cytokines while the fat pads release adipokines such as leptin, resistin, adiponectin, visfatin, and chemerin [7]. Although the role of adipokines in OA remains to be conclusively elucidated, many studies have implied that they may act as chemokines and increase matrix-degrading enzymes matrix metalloproteinase (MMP) and a disintegrin and metalloproteinase with thrombospondin motifs (ADAMTS) [7-9], nitric oxide synthase (NOS) [10], Toll-like receptor (TLR) [7], and other cytokine production [7, 11]. Additionally, joint-associated fat pads are innervated by Cfiber neurons which release substance $P$, thereby increasing pain sensitivity, proinflammatory cytokine production, and vascular permeability $[12,13]$. This series of events leads to the release of damage-associated molecular patterns (DAMPs), or alarmins, from the extracellular matrix (ECM) by both direct trauma and the action of MMPs and ADAMTS, as well as from neutrophils and monocytes. DAMPs stimulate TLRs on macrophages and chondrocytes, inducing a strong upregulation of catabolic markers (MMPs 1, 3, 9, and 13, IL6 , IL-8, and monocyte chemotactic protein 1) and cytokines $\mathrm{TNF} \alpha$ and IL- $1 \beta$ by way of $\mathrm{NF} \kappa \mathrm{B}$ activation, which is the master regulator in immune response [14-16]. This chronic activation of TLRs leads to their upregulation in chondrocytes [15] and increased sensitivity [16].

The actions of complement are further demonstrating the significant role played by the innate immune system in early OA. Wang et al. reported that complement expression and activation were abnormally high in OA synovium, especially in early OA, seen in Figure 1. Additionally, the membrane attack complex (MAC, C5b-9) was present surrounding chondrocytes in late $\mathrm{OA}$ [17]. MAC directly damages the cell membrane but also stimulates MMP, ADAMTS, and chemokine production in chondrocytes, leading to increased chondrocyte destruction, catabolism of cartilage, and leukocyte infiltration. MMPs release components of the extracellular matrix, such as fibromodulin and aggrecan, which further induce MAC formation. To further assess the role of complement, Wang et al. knocked out C5 in mice and observed that, compared to $\mathrm{C}^{+}$controls, the $\mathrm{C}^{-}$mice showed no significant synovitis or cartilage loss 8-12 weeks status post $(\mathrm{s} / \mathrm{p})$ medial meniscectomy, a surgery that can induce OA. Furthermore, $\mathrm{C6}^{-}$mice developed about half the synovial degeneration as $\mathrm{C}^{+}$mice s/p medial meniscectomy. CD59, a MAC inhibitor, was also knocked out in another mouse model, and these mice developed more severe OA compared to controls [17]. In another study, Busby Jr. et al. found that

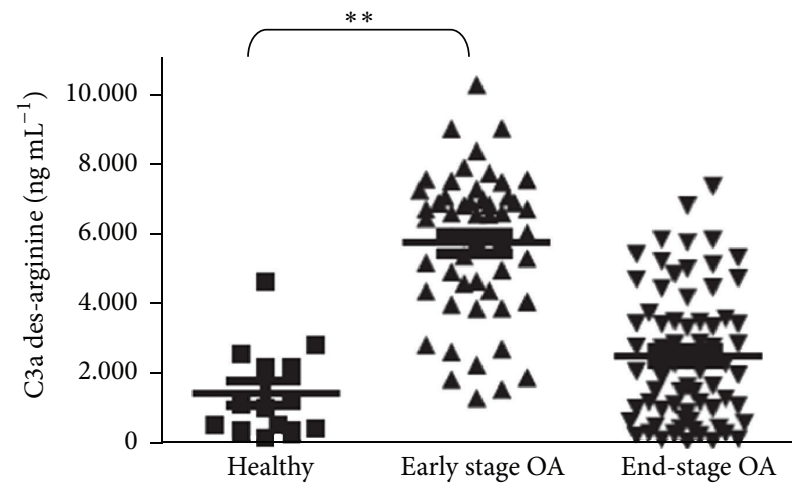

FIGURE 1: Complement synovial infiltration in the early pathogenesis of OA. ELISA quantification of C3a des-arginine in synovial fluid of healthy $(n=14)$, early-stage OA $(n=52)$, and end-stage OA $(n=69)$ patients. C3a des-arginine is a carboxypeptidase-cleaved, stable form of C3a that is generated from C3 during activation of the complement cascade. ${ }^{* *} P \leq 0.01$ by one-way analysis of variance (ANOVA) and Dunnett's post hoc test (reproduction of image with permission and modified caption from Wang et al. [17]).

inhibiting C1s, a serine protease involved in the initiation of the classic activation pathway, promoted favorable joint architecture in dogs. One mechanism by which Cls exerts its effects is by cleaving chondroprotective IGFBP-5 [18].

Other innate immune cells have also been found to play a role in pathogenesis. NK cells have been found in the synovium of OA patients, in one study exhibiting a $\mathrm{CD} 16^{+} \mathrm{CD} 56^{+}$phenotype both with and without granzymes A and B [19]. Granzyme A and B expression correlates with cytolytic potency in vitro [19]. In another study, NK cells were identified within OA synovia with a $\mathrm{CD} 16^{-} \mathrm{CD} 56^{+}$ phenotype without granzyme expression. Additionally, these cells demonstrated poor production of interferon $\gamma$ (IFN $\gamma$ ), a cytokine central to osteoclastogenesis, upon stimulation in vitro [20]. In yet another study, granzymes $A$ and $B$ could be identified in the synovia from OA, RA, and reactive arthritis patients [21]. These findings imply that, in OA joints, NK cells can be of an active, cytolytic phenotype, or of an exhaustive, postactivation versus immunoregulatory phenotype. Granzymes A and B, exclusively produced by cytolytic lymphocytes, were identified both intracellularly in NK cells and in the synovia of OA patients [19, 21]. While granzyme presence in the synovium could be explained by $\mathrm{T}$ cells, the exclusiveness of this is unlikely. The production and release of granzymes $[19,21]$ support the notion of an activation/postactivation phenotype theory of NK cell involvement [20]. Of note, Huss et al., who identified mostly $\mathrm{CD} 16^{-} \mathrm{CD} 56^{+} \mathrm{NK}$ cells negative for granzymes and suggested that NK cells are of the immunoregulatory phenotype [20], performed their analysis on patients undergoing primary or revision joint replacement, indicative of late OA patients. Concordantly, IFN $\gamma$ production and degranulation of NK cells were significantly lower after in vitro stimulation of synovial tissue taken from revision versus primary joint replacement patients (degranulation of $2 \%$ and $7 \%$, resp., $P<0.05)[20]$. The decreased sensitivity of synovial NK cells 
to stimulation in revision versus primary joint replacement patients demonstrates evidence for an exhaustive NK cell phenotype in late OA. Most likely there is a combination of both activating and immunoregulatory roles played by $\mathrm{NK}$ cells in OA pathogenesis.

Mast cells have been identified in the synovium of OA patients [22-24], and in one study their counts were found to have a positive correlation with total cellular infiltrate $\left(r_{s}=\right.$ $0.82, P=0.0141$ ) [19]. Interestingly, no correlation between ESR and mast cell count or total cellular infiltrate was found, suggesting only local effects in the joint microenvironment inconsistent with markers of systemic inflammation or disease process [22]. This point is a major barrier to diagnosing and monitoring $\mathrm{OA}$ and is expounded upon in later sections. Mast cells are a potent regulator of vascular permeability, and they may play a crucial role in leukocyte recruitment to OA joints. Degranulated mast cells have been found in OA synovium [23], and Buckley et al. discovered a selective expansion and higher ratio of mast cell tryptase phenotype in OA synovium, a phenotype consistent with degranulation [24].

While the significance of neutrophils in synovial disease is well characterized in RA, the role of neutrophils in OA is relatively unknown. Neutrophils are found in varying levels in the synovium of OA patients but generally are found only in small numbers if present at all [5]. However, human neutrophil peptides 1-3 (HNP1-3), $\alpha$-defensins, were found in the synovial tissue of both OA and RA patients in one study [25]. Interestingly, stimulation with TNF $\alpha$ led to the inhibition of HNP1-3 levels in the synovium of OA patients but not RA patients. The authors concluded that this was most likely due to desensitization of TNF receptors in RA synovia. Paired with the finding that HNP1-3 stimulates macrophages to release TNF $\alpha$ [26], the authors concluded that TNF forms a negative feedback loop with HNP1-3 [25]. If HNP1-3 release does precede the actions of TNF $\alpha$, this would suggest that neutrophils play a role in early OA pathogenesis, as TNF $\alpha$ is a central mediator of the disease process. In another study, neutrophil gelatinase-associated lipocalin (NGAL) was found in complex with MMP-9 in OA synovia. NGAL served to decrease degradation of MMP-9 [27], found to be the predominant gelatinase in actively resorbing cartilage [28]. In the presence of NGAL-MMP-9, increased levels of glycosaminoglycan were released from cartilage explants in vitro [27]. The role of the innate immune response in early OA pathogenesis is summarized in a stepwise fashion below.

(I) Trauma to the joint is absorbed by subchondral bone and fat pads.

(II) Cytokines, MMPs, and ADAMTS are released.

(III) Direct trauma and MMP/ADAMTS activity release DAMPs which stimulate TLRs.

(IV) TLR activation stimulates $\mathrm{NF} \kappa \mathrm{B}$, the release of cytokines (mainly TNF $\alpha$ and IL-1 $\beta$ ), macrophages, complement, catabolic pathways in chondrocytes, other innate immune cells, and ultimately the adaptive immune response.
(V) Chronic cascading increases TLR expression and receptor sensitivity, further increasing inflammation.

2.2. Adaptive Response. Actions of the innate immune system inevitably lead to activation of the adaptive immune system, increasing inflammation and damage to the joints. $\mathrm{TNF} \alpha$ and IL- $1 \beta$ are the dominant and most abundant cytokines implicated in OA [5]. They act independently of each other and additively to shift synovial tissue homeostasis towards catabolism [29, 30]. Mechanisms of this shift include increased resorption and inhibition of proteoglycans in cartilage, production of MMPs and chemokines, endothelium activation, and induction of apoptosis in chondrocytes [31, 32]. This leads to increased macrophage and $\mathrm{CD}^{+} \mathrm{T}$ cell infiltration, blood vessel formation by increased vascular endothelial growth factor (VEGF), and increased cyclooxygenase-2 level [33]. Macrophages and T cells, specifically of the $\mathrm{CD}^{+}$Th1 subtype $[34,35]$, are the most abundant cell types found in the synovium of OA patients $[5,36]$. Their activation initiates a repetitive cascade of events, activating both the innate and adaptive immune systems, and this propagating inflammation destroys increasing amounts of cartilage, decreasing function and increasing morbidity. T cells are responsible for enhanced stimulation of macrophages and the activation of B cells. Autoreactive B cells further damage cellular integrity and increase inflammation by producing autoantibodies specific for cartilage cell surface proteins such as osteopontin and collagen. Elevated titers of these autoantibodies were found in the sera from OA patients compared to controls [31]. The adaptive immune response is summarized in stepwise fashion below.

(I) Cytokine release and increased vascular permeability lead to T-cell infiltration.

(II) $\mathrm{T}$ cells release chemokines and cytokines including IFN $\gamma$, further stimulating macrophages.

(III) Antigen presentation activates B cells.

(IV) B cells release IL-6, increasing acute phase reactants, and produce autoantibodies causing direct damage to cartilage.

(V) Lymphocyte and macrophage activation in the joint microenvironment lead to a chronic, relapsing course of inflammation.

\section{Early Diagnosis and Treatment}

3.1. Imaging Techniques. Anatomic imaging techniques, such as radiography and magnetic resonance imaging (MRI), are currently used for epidemiological studies and clinical trials $[37,38]$. Plain radiography is the traditional approach to monitoring progression of disease by clinicians; however, the drawbacks of this approach are apparent: insensitivity to change, nonspecificity, susceptibility to measurement error due to change in positioning, and inability to detect early stages of disease $[39,40]$. MRI is regarded as sensitive, valid, and reproducible in that it can assess abnormalities of the whole-joint structure including cartilage degeneration [41], subchondral bone marrow lesions $[42,43]$, meniscal defects 


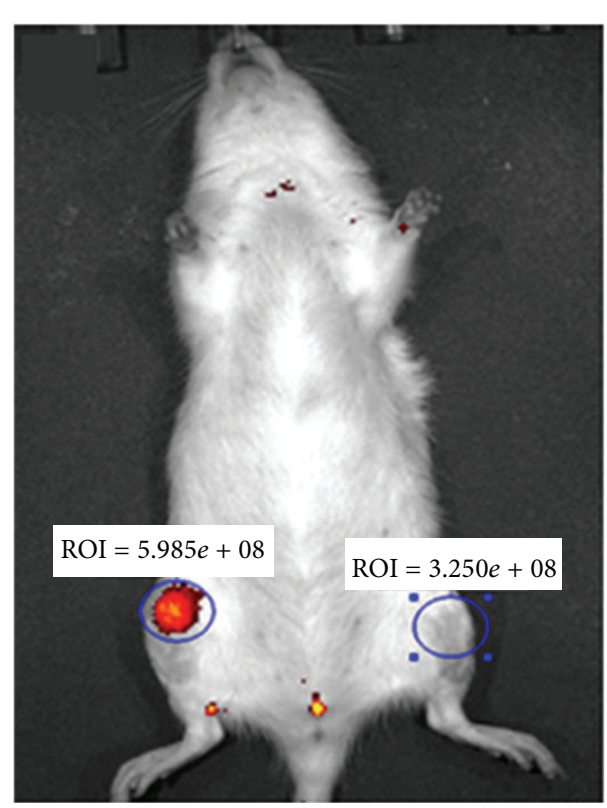

(a)

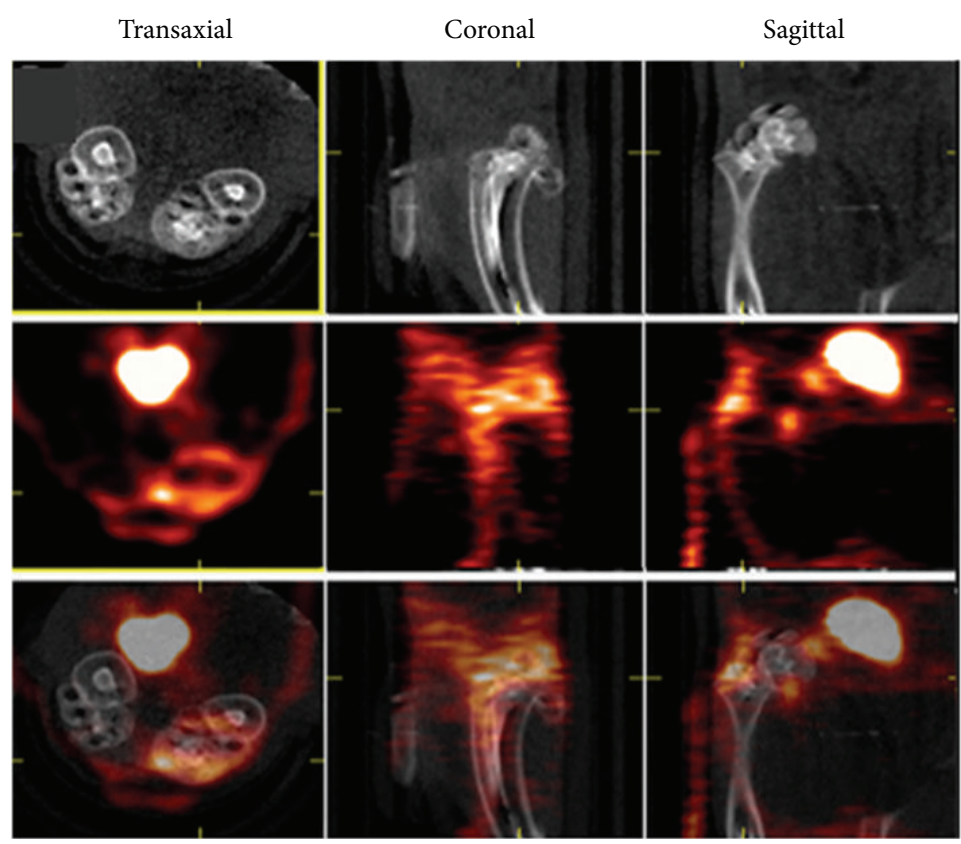

(b)

FIGURE 2: In vivo imaging of inflammation with two cFLFLF-derived probes in the rat knee joints treated with (right knee) or without (left knee) monoiodoacetate (MIA). (a) CFLFLF-PEG-Cy 7 probe with animal back down, at day 5 after MIA injection; (b) cFLFLF-PEG-DOTA${ }^{64} \mathrm{Cu}$ with animal back up, at day 5 after MIA injection (upper column: micro-CT; middle column: micro-PET; lower column: fused).

[44], and joint effusion and synovitis [45]. However, even MRI is not sensitive enough to detect the early immune cell infiltration of joints in OA, as inflammation far precedes cartilage destruction marked by radiographic change [46].

There is a substantial need to develop imaging techniques that can visualize the activity of the disease process itself, rather than measure structural changes that are a result of the disease process [47]. In this regard, a few reports have been published on the use of functional nuclear imaging techniques, such as positron emission tomography (PET) and planar or single-photon emission computed tomography (SPECT), for monitoring the inflammatory process of OA [48]. ${ }^{18} \mathrm{~F}$-2-Fluoro-2-deoxy-D-glucose and ${ }^{111}$ In-diethylene triamine pentaacetic acid-folates have been explored as imaging tracers for OA because of respective increased metabolism of glucoses and elevated expression of folate receptors in activated immune cells [49]. Although these tracers have demonstrated some promise in clinical trials as well as in experimental OA models, they are likely not in use due to the lack of an inflammation-specific window of opportunity for imaging.

Alternatively, formyl peptide receptor (FPR) is primarily expressed on activated leukocytes as a defense mechanism to detect and trigger an immune cell response to inflammation caused by infections in a time and concentration dependent manner [50]. In the past years, based on a FPR-specific binding peptide, cFLFLF, we have successfully utilized the cFLFLF-PEG modules to build PET (1,4,7,10-tetraazacyclododecane-1,4,7,10-tetraacetic acid${ }^{64} \mathrm{Cu}$, also known as DOTA- $\left.{ }^{64} \mathrm{Cu}\right)$, SPECT $\left({ }^{99 \mathrm{~m}} \mathrm{Tc}\right)$, and optical (cyanine-5 and cyanine-7) imaging probes and exhibited excellent imaging in a variety of animal inflammation models [51-55]. The cFLFLFK-Cy-7 probe is now commercially available (Kerafast, Inc.) and cFLFLF-based probes have been developed enthusiastically for animal imaging by the broader research community [56-58].

We are currently exploring if a cFLFLF-based SPECT imaging approach is feasible to monitor aseptic inflammation with a particular interest in OA. To this end, an acute model was created by intra-articular injection of monoiodoacetate for near-infrared fluorescence (NIRF) or PET imaging of inflammatory cells during OA development in rat knee joints. As shown in Figure 2, the inflamed joints were well imaged by either a NIRF probe cFLFLF-PEG-Cy 7 (Figure 2(a)) or a PET probe cFLFLF-PEG-DOTA- ${ }^{64} \mathrm{Cu}$ (Figure 2(b)). If available in the clinic, use of this SPECT technique can facilitate early detection and monitoring of the recruitment of innate leukocytes during OA development, allow correct characterization and diagnosis to direct early appropriate intervention, and improve long-term outcomes in OA patients [59].

As a caveat, FPR expression in fibroblasts and mesenchymal stem cells (MSCs) has been demonstrated [60, 61]. However, these MSCs and fibroblasts likely serve to repair tissue, initiate tissue remodeling, and mediate leukocyte infiltration in response to the acute chemotactic stimuli of formyl peptide, thereby still reflecting early changes on imaging. The actions of fibroblasts are noted in Tables 1 and 2, respectively. MSCs decrease inflammation, and overexpression of FPR in these cells is currently being studied as potential therapy in chronic disease such as cystic fibrosis [61]. Additionally, FPR ligands have been shown to decrease inflammation in joints and have even been suggested as potential therapies for RA 
TABle 3: Probes for mediators of inflammation in modern imaging techniques.

\begin{tabular}{|c|c|}
\hline Cell type or protein & Probe \\
\hline Macrophage & (i) ${ }^{18}$ F-FDG (PET) $[98,99]$ \\
\hline $\mathrm{CD}^{+} \mathrm{T}$ cell & $\begin{array}{l}\text { (i) }{ }^{64} \mathrm{Cu}-\mathrm{PTSM}(\mathrm{PET})[100] \\
\text { (ii) }{ }^{18} \mathrm{~F}-\mathrm{FB}-\mathrm{IL}-2(\mathrm{PET})[99]\end{array}$ \\
\hline B cell & (i) ${ }^{124}$ I-rituximab (PET) [101] \\
\hline Neutrophil & $\begin{array}{c}\text { (i) cFLFLF-PEG-Cy } 7 \text { (NIRF) } \\
\text { (ii) cFLFLF-PEG-DOTA- }{ }^{64} \mathrm{Cu}(\mathrm{PET})\end{array}$ \\
\hline Mast cell & (i) Ligand 1 (in vitro) [102] \\
\hline TNF $\alpha$ & (i) ${ }^{64} \mathrm{Cu}$-DOTA-etanercept (PET) [103] \\
\hline Complement & $\begin{array}{l}\text { (i) USPIO-conjugated anti-C3mab } \\
\text { (T2-MRI) [104] }\end{array}$ \\
\hline MMP & $\begin{array}{c}\text { (i) }{ }^{124} \mathrm{I}-\mathrm{HO}-\mathrm{MPI}(\mathrm{CGS} 27023 \mathrm{~A})(\mathrm{PET}) \\
{[105]}\end{array}$ \\
\hline
\end{tabular}

[62]. Regarding the utilization of FPR as an imaging target in early OA, the actions of MSCs, fibroblasts, and FPR ligands, while noteworthy, should have little to no effect or have not yet been discovered. Probes for many cell types and mediators of inflammation mentioned in this paper are displayed in Table 3 and Figure 3.

3.2. Biomarkers. To date, many barriers exist in identifying biomarkers reflective of $\mathrm{OA}$ severity; histochemical findings have yet to be linked to clinical traits such as pain and function. Foremost, as evidenced in the next section, inflammation in $\mathrm{OA}$ is not only local but also systemic, making standard systemic measurements from individual to individual difficult. The confounding factors in systemic inflammation are immeasurable: age, genetics, diet, activity, kidney function, liver function, weight, and other comorbidities to name a few [63]. Numerous biomarkers have been thought to show promise in recent studies, such as serum cartilage oligomeric matrix protein and urine C-terminal cross-linked telopeptide type II collagen levels, but these are nonspecific to cartilage $[63,64]$. Complicating the lack in specificity of inflammatory biomarkers is that measurements in OA patients are drawn once disease is already established. The ability is compromised to determine baseline patient values, cut-off values distinguishing normal from abnormal, and markers that are pathological rather than released naturally or concurrently. Another major barrier limiting the identification of both biomarkers and effective treatment is the unfortunate discrepancy between in vitro and in vivo studies. Decreasing specific mediators of inflammation has thus far not led to improved pain score or prognosis in vivo.

For these reasons testing biomarker levels in synovial fluid seems appropriate. However, the natural microenvironment between individual joints varies, making standard measurements difficult to implement [63]. This is evidenced by the unique infrapatellar fat pad of the knee, which greatly contributes to OA pathogenesis by way of adipokine release. Additionally, extracting synovial fluid is restricted to the larger joints and carries risks as compared to drawing blood. Finally, different phenotypes of disease presumably
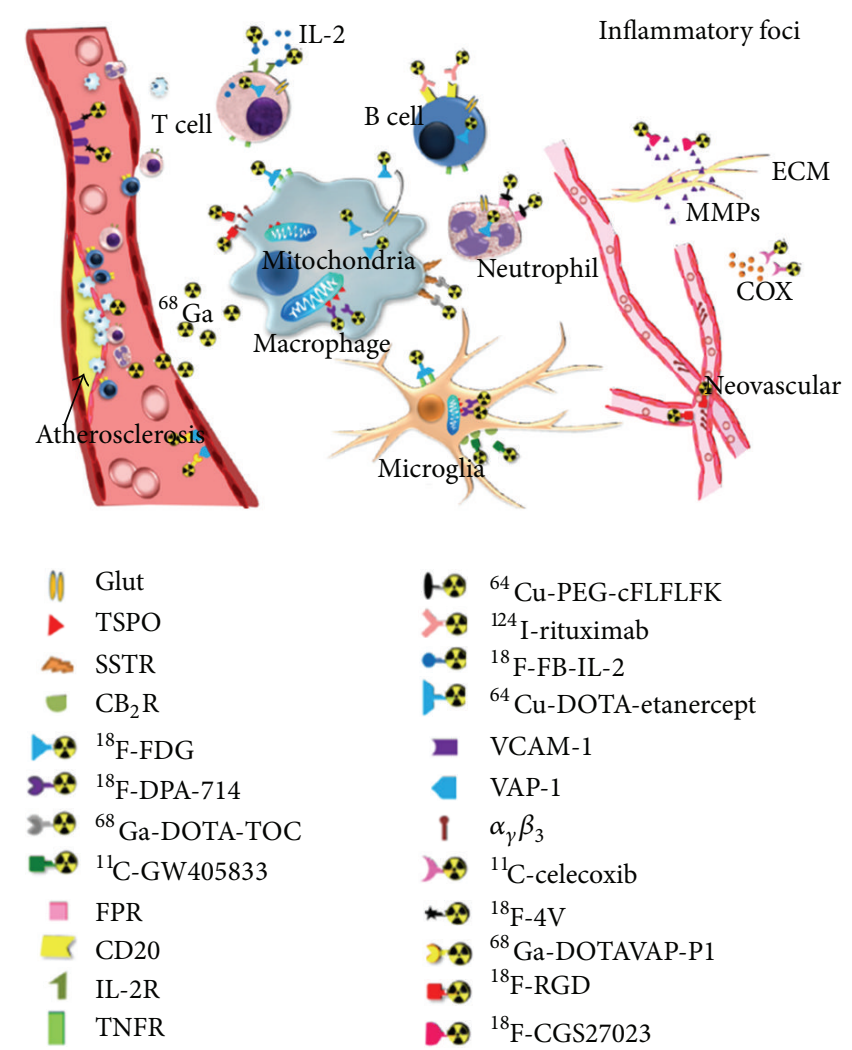

$$
\begin{aligned}
& \text { 19 }{ }^{64} \text { Cu-PEG-cFLFLFK } \\
& >{ }^{124} \mathrm{I} \text {-rituximab } \\
& \text { a } 18 \text { F-FB-IL-2 } \\
& \text { - }{ }^{64} \mathrm{Cu}-\mathrm{DOTA} \text {-etanercept } \\
& \text { I VCAM-1 } \\
& \text { - VAP-1 } \\
& \text { ? } \alpha_{\gamma} \beta_{3} \\
& \text { ) }{ }^{11} \mathrm{C} \text {-celecoxib } \\
& \text {-28 }{ }^{18} \mathrm{~F}-4 \mathrm{~V} \\
& { }^{68} \text { Ga-DOTAVAP-P1 } \\
& { }^{18} \mathrm{~F}-\mathrm{RGD} \\
& { }^{18} \text { F-CGS27023 }
\end{aligned}
$$

FIgURE 3: Inflammatory biomarkers in PET imaging (reproduced with permission from Wu et al. [99]).

involve diverse biomarkers, pathways, and sequelae [63]. As evidenced by Table 1 , T cells $[34,65]$ and NK cells $[19,20,66]$ have been shown to possess exhaustive and chronic phenotypes, respectively, in late versus early disease, demonstrating that early disease is the primary mechanism responsible for changes in the joint microenvironment, underlining the importance of identifying these changes.

3.3. Hurdles to Treatment. The significance of the innate immune system in early OA becomes evident, as it leads to direct chondrocyte and cartilage destruction as well as $\mathrm{NF} \kappa \mathrm{B}$ activation with pronounced redundancy and perpetuation. As stated previously, $\mathrm{NF} \kappa \mathrm{B}$ is the master regulator of the immune response. It is involved in the activation of complement, defensins, adhesions, and caspase- 1 , as well as the production of cytokines, reactive oxygen species (ROS), and NO. Despite the attractiveness of targeting $\mathrm{NF} \kappa \mathrm{B}$ in disease-modifying therapy, it is an unreliable target in large part due to its universal role in normal cellular signaling. Its modulation has a significant side effect profile; however natural health products such as those found in grapes and green tea have shown promise but need further study [67].

The difficulty in treating $\mathrm{OA}$ is that once local and systemic inflammation is established, debilitative changes in affected joints are difficult to control. OA is both affected by and contributing to a baseline proinflammatory state, such as that seen in senescence, metabolic syndrome, and 


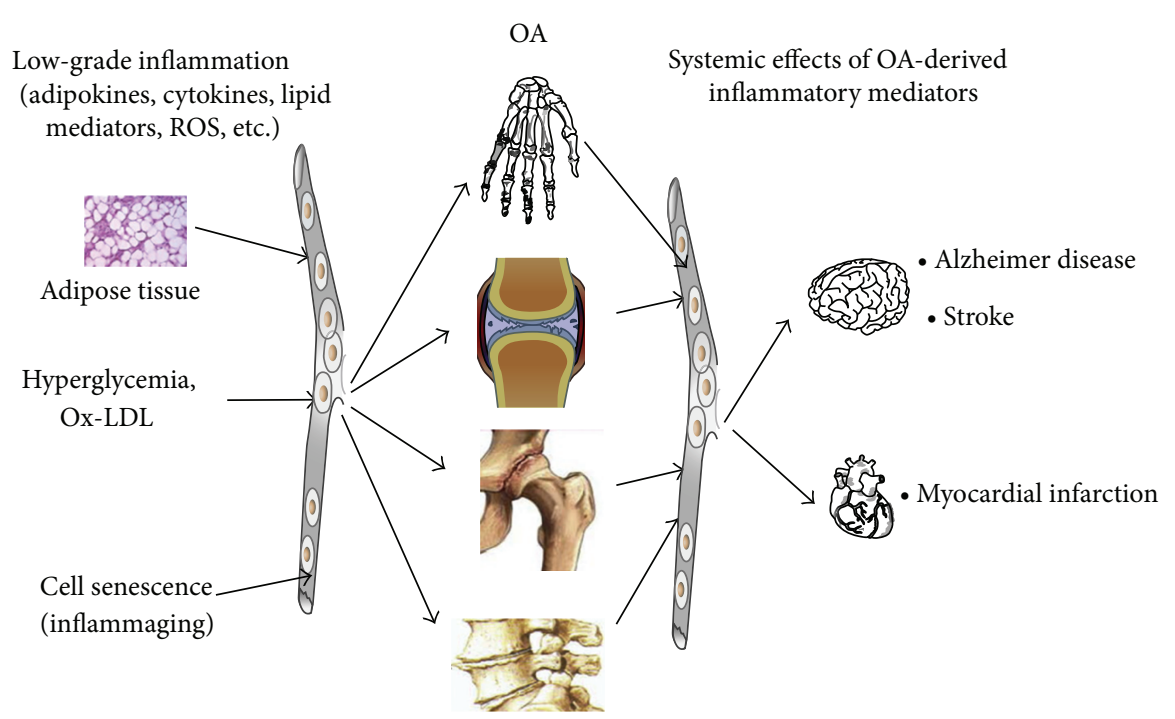

FIGURE 4: Model for role of systemic proinflammatory state and OA. Inflammatory mediators released into blood enter the joint exacerbating $\mathrm{OA}$, which releases its own mediators of inflammation leading to increased systemic inflammation (reproduced with permission from Berenbaum [6]).

Alzheimer's disease amongst others (Figure 4) [4]. For example, Berenbaum et al. found that a high fat diet increased inflammation in the acute phase of OA [7]. In another study, Kyrkanides et al. found that inducing OA in mice genetically susceptible to Alzheimer's disease exacerbated and accelerated neuroinflammation, increasing the number and size of amyloid plaques [68]. Many therapies, including anti-TNF $\alpha$ and anti-IL-1 $\beta$ therapy, have been shown to decrease inflammation but fail to significantly improve function or prognosis in established OA patients $[3,4]$. Pain levels have been shown to have a statistically significant correlation with level of change in synovitis $(r=0.21$, $P=0.0003$ ), but not cartilage destruction or baseline level of synovitis [69]. This correlation is only modest and does nothing but supporting the notion that a relative increase in inflammation will increase perception of pain. There is a disconnection between biomarkers of disease, radiographic change, and symptomology, complicating treatment. Degenerative change in OA can occur under two months following trauma [70], and epigenetics has been shown to play a role in mediating the acute inflammatory changes driven by the altered joint microenvironment [71]. It is for these reasons that we hypothesize that addressing early inflammatory change in the synovium consistent with $\mathrm{OA}$ is crucial in modulating disease progression and therefore patient disability. Therapies that have failed to show benefit to date may be effective when implemented at an appropriate stage of disease. Future research should be targeted toward identifying at-risk patients and early intervention.

\section{Perspectives}

Pharmacological treatment to date has had varying effects on symptomology, but disease modulation has yet to be attained. Common modalities include NSAIDS, corticosteroids, chondroitin sulfate, and glucosamine [72]. These treatments are variably effective on an individual basis and often only provide temporary relief and are needed to be repeated chronically. Trials of anti-TNF $\alpha$ and anti-IL-1 $\beta$ therapy for disease modulation have been unsuccessful despite the dominance of TNF $\alpha$ and IL-1 $\beta$ in pathogenesis [4]. Chevalier et al. concluded that IL-1 $\beta$ antagonism may benefit patients with baseline high levels of pain if administered in low, frequent intra-articular (IA) injections to avoid neutropenia and serious infection [73]. One in vivo study revealed that IA injection of lubricin up to two weeks after injury reduced severity of $\mathrm{OA}$ in mice, while local antioxidants such as $\mathrm{N}$ acetylcysteine after injury showed promise in vitro $[74,75]$. The proposed benefit of these treatments administered soon after injury in injury-induced $\mathrm{OA}$ underlines the significance of early intervention in OA pathogenesis. Treatment with fibroblast growth factor 18, which is specific for the anabolic FGFR-3 versus the catabolic FGFR-1, is currently on trial [71].

We believe that regular screening is needed and is justified as $\mathrm{OA}$ is ubiquitous in seniors aged over 65 , is clinically present in $13.9 \%$ of US adults aged 25 or above, and is a leading cause of disability and hospitalization in the USA $[1,2,72]$. However, further studies are needed in order to establish guidelines for screening. We recommend that regular screening for OA be implemented on an outpatient basis. Special attention should be given to patients of 65 years or above and patients with metabolic syndrome, Alzheimer's disease, or other systemic proinflammatory states. Candidate markers for screening should continue to be researched with particular attention paid to local articular levels. IL6, complement, and ratio of FGFR-3/FGFR-1 should be considered.

Additionally, the role of physical, imaging, or combination diagnostic paradigms must be considered. Contrastenhanced MRI and power Doppler ultrasound are the leading imaging modalities for synovitis [46]. Identifying early and specific changes in OA may best be visualized 
using PET, NIRF, or SPECT imaging. Many probes for cells and proteins involved in $\mathrm{OA}$ pathogenesis are listed in Table 3 and Figure 3. We are currently developing a Tc99m-cFLFLF/SPECT technique to visualize early leukocyte recruitment in OA joints based on a preliminary in vivo study (Figure 2). While our probe is not $100 \%$ specific for leukocytes, we are currently in the process of identifying more specific receptors.

As changes in the joint consistent with OA can occur rapidly following injury and are associated with inflammation, intervention should be aimed at the early reactive phase of OA pathogenesis [70]. Importantly, past therapeutic trials may have failed due to attempted intervention at irreversible stages of disease. Wang et al. showed that knocking out components of the complement cascade greatly reduced incidence of $\mathrm{OA}$ in mice [17] and this strategy for treatment management should be further researched. A study assessing whether there is an increased relative risk of OA diagnosis and severity in patients with paroxysmal nocturnal hemoglobinuria could be beneficial in this regard. Anticomplement therapy should initially be attempted locally to narrow the focus of treatment and lower the incidence of potential severe infection.

While disease modification in OA still eludes the medical community, recent advances in pathogenesis and understanding of the disease process beseech hope to solving the riddle of a ubiquitous, costly disease that significantly diminishes quality of life in millions of patients. With guided further research and international collaboration, we believe that early detection and intervention in OA are possible. Due to the lack of success and discrepancy of disease modulation between in vivo and in vitro studies, the significance of identifying patients in the early phase of disease becomes paramount in experimenting with detection and treatment of the disease process. Screening must be implemented in highrisk patients, and early, aggressive treatment is necessary and mandated to avoid substantial morbidity.

\section{Conflict of Interests}

The authors declare that there is no conflict of interests regarding the publication of this paper.

\section{References}

[1] L. Murphy and C. G. Helmick, "The impact of osteoarthritis in the United States: a population-health perspective: a population-based review of the fourth most common cause of hospitalization in U.S. adults," American Journal of Nursing, vol. 112, no. 3, pp. S13-S19, 2012.

[2] R. C. Lawrence, D. T. Felson, C. G. Helmick et al., "Estimates of the prevalence of arthritis and other rheumatic conditions in the United States. Part II," Arthritis and Rheumatism, vol. 58, no. 1, pp. 26-35, 2008.

[3] C. J. Malemud, "Anticytokine therapy for osteoarthritis: evidence to date," Drugs and Aging, vol. 27, no. 2, pp. 95-115, 2010.

[4] A. L. G. Calich, D. S. Domiciano, and R. Fuller, "Osteoarthritis: can anti-cytokine therapy play a role in treatment?" Clinical Rheumatology, vol. 29, no. 5, pp. 451-455, 2010.
[5] B. J. E. de Lange-Brokaar, A. Ioan-Facsinay, G. J. V. M. van Osch et al., "Synovial inflammation, immune cells and their cytokines in osteoarthritis: a review," Osteoarthritis and Cartilage, vol. 20, no. 12, pp. 1484-1499, 2012.

[6] F. Berenbaum, "Osteoarthritis as an inflammatory disease (osteoarthritis is not osteoarthrosis!)," Osteoarthritis and Cartilage, vol. 21, no. 1, pp. 16-21, 2013.

[7] F. Berenbaum, F. Eymard, and X. Houard, "Osteoarthritis, inflammation and obesity," Current Opinion in Rheumatology, vol. 25, no. 1, pp. 114-118, 2013.

[8] K. O. Yaykasli, O. F. Hatipoglu, E. Yaykasli et al., "Leptin induces ADAMTS-4, ADAMTS-5, and ADAMTS-9 genes expression by mitogen-activated protein kinases and NF- $\kappa$ B signaling pathways in human chondrocytes," Cell Biology International, 2014.

[9] W. Hui, G. J. Litherland, M. S. Elias et al., "Leptin produced by joint white adipose tissue induces cartilage degradation via upregulation and activation of matrix metalloproteinases," Annals of the Rheumatic Diseases, vol. 71, no. 3, pp. 455-462, 2012.

[10] M. Otero, R. Lago, R. Gómez, F. Lago, J. J. Gomez-Reino, and O. Gualillo, "Phosphatidylinositol 3-kinase, MEK-1 and p38 mediate leptin/interferon-gamma synergistic NOS type II induction in chondrocytes," Life Sciences, vol. 81, no. 19-20, pp. 1452-1460, 2007.

[11] P.-J. Francin, A. Abot, C. Guillaume et al., "Association between adiponectin and cartilage degradation in human osteoarthritis," Osteoarthritis and Cartilage, vol. 22, no. 3, pp. 519-526, 2014.

[12] S. Clockaerts, Y. M. Bastiaansen-Jenniskens, J. Runhaar et al., "The infrapatellar fat pad should be considered as an active osteoarthritic joint tissue: a narrative review," Osteoarthritis and Cartilage, vol. 18, no. 7, pp. 876-882, 2010.

[13] M. Bohnsack, F. Meier, G. F. Walter et al., "Distribution of substance-P nerves inside the infrapatellar fat pad and the adjacent synovial tissue: a neurohistological approach to anterior knee pain syndrome," Archives of Orthopaedic and Trauma Surgery, vol. 125, no. 9, pp. 592-597, 2005.

[14] D. H. Sohn, J. Sokolove, O. Sharpe et al., "Plasma proteins present in osteoarthritic synovial fluid can stimulate cytokine production via Toll-like receptor 4," Arthritis Research and Therapy, vol. 14, article R7, 2012.

[15] S.-L. Su, C.-D. Tsai, C.-H. Lee, D. M. Salter, and H.-S. Lee, "Expression and regulation of Toll-like receptor 2 by IL-1 $\beta$ and fibronectin fragments in human articular chondrocytes," Osteoarthritis and Cartilage, vol. 13, no. 10, pp. 879-886, 2005.

[16] R. F. P. Schelbergen, A. B. Blom, M. H. J. van den Bosch et al., "Alarmins S100A8 and S100A9 elicit a catabolic effect in human osteoarthritic chondrocytes that is dependent on tolllike receptor 4," Arthritis \& Rheumatism, vol. 64, no. 5, pp. 14771487, 2012.

[17] Q. Wang, A. L. Rozelle, C. M. Lepus et al., "Identification of a central role for complement in osteoarthritis," Nature Medicine, vol. 17, no. 12, pp. 1674-1679, 2011.

[18] W. H. Busby Jr., S. A. Yocum, M. Rowland et al., "Complement $1 \mathrm{~s}$ is the serine protease that cleaves IGFBP-5 in human osteoarthritic joint fluid," Osteoarthritis and Cartilage, vol. 17, no. 4, pp. 547-555, 2009.

[19] J. A. Kummer, P. P. Tak, B. M. N. Brinkman et al., "Expression of granzymes A and B in synovial tissue from patients with rheumatoid arthritis and osteoarthritis," Clinical Immunology and Immunopathology, vol. 73, no. 1, pp. 88-95, 1994. 
[20] R. S. Huss, J. I. Huddleston, S. B. Goodman, E. C. Butcher, and B. A. Zabel, "Synovial tissue-infiltrating natural killer cells in osteoarthritis and periprosthetic inflammation," Arthritis \& Rheumatism, vol. 62, no. 12, pp. 3799-3805, 2010.

[21] P. P. Tak, L. Spaeny-Dekking, M. C. Kraan, F. C. Breedveld, C. J. Froelich, and C. E. Hack, "The levels of soluble granzyme $\mathrm{A}$ and $\mathrm{B}$ are elevated in plasma and synovial fluid of patients with rheumatoid arthritis (RA)," Clinical and Experimental Immunology, vol. 116, no. 2, pp. 366-370, 1999.

[22] T. E. Damsgaard, F. B. Sørensen, T. Herlin, and P. O. Schiøtz, "Stereological quantification of mast cells in human synovium," APMIS, vol. 107, no. 3, pp. 311-317, 1999.

[23] G. Dean, J. A. Hoyland, J. Denton, R. P. Donn, and A. J. Freemont, "Mast cells in the synovium and synovial fluid in osteoarthritis," British Journal of Rheumatology, vol. 32, no. 8, pp. 671-675, 1993.

[24] M. G. Buckley, P. J. Gallagher, and A. F. Walls, "Mast cell subpopulations in the synovial tissue of patients with osteoarthritis: selective increase in numbers of tryptase-positive, chymasenegative mast cells," The Journal of Pathology, vol. 186, no. 1, pp. 67-74, 1998.

[25] B. Riepl, S. Grässel, R. Wiest, M. Fleck, and R. H. Straub, “Tumor necrosis factor and norepinephrine lower the levels of human neutrophil peptides 1-3 secretion by mixed synovial tissue cultures in osteoarthritis and rheumatoid arthritis," Arthritis Research and Therapy, vol. 12, article R110, 2010.

[26] O. Soehnlein, Y. Kai-Larsen, R. Frithiof et al., "Neutrophil primary granule proteins HBP and HNP1-3 boost bacterial phagocytosis by human and murine macrophages," The Journal of Clinical Investigation, vol. 118, no. 10, pp. 3491-3502, 2008.

[27] K. Gupta, M. Shukla, J. B. Cowland, C. J. Malemud, and T. M. Haqqi, "Neutrophil gelatinase-associated lipocalin is expressed in osteoarthritis and forms a complex with matrix metalloproteinase 9," Arthritis \& Rheumatism, vol. 56, no. 10, pp. 3326-3335, 2007.

[28] J. M. Milner, A. D. Rowan, T. E. Cawston, and D. A. Young, "Metalloproteinase and inhibitor expression profiling of resorbing cartilage reveals pro-collagenase activation as a critical step for collagenolysis," Arthritis Research \& Therapy, vol. 8, no. 5, article R142, 2006.

[29] J. Bondeson, A. B. Blom, S. Wainwright, C. Hughes, B. Caterson, and W. B. van den Berg, "The role of synovial macrophages and macrophage-produced mediators in driving inflammatory and destructive responses in osteoarthritis," Arthritis and Rheumatism, vol. 62, no. 3, pp. 647-657, 2010.

[30] J. Saklatvala, "Tumour necrosis factor $\alpha$ stimulates resorption and inhibits synthesis of proteoglycan in cartilage," Nature, vol. 322, no. 6079, pp. 547-549, 1986.

[31] A. Haseeb and T. M. Haqqi, "Immunopathogenesis of osteoarthritis," Clinical Immunology, vol. 146, no. 3, pp. 185-196, 2013.

[32] V. Lefebvre, C. Peeters-Joris, and G. Vaes, "Modulation by interleukin 1 and tumor necrosis factor $\alpha$ of production of collagenase, tissue inhibitor of metalloproteinases and collagen types in differentiated and dedifferentiated articular chondrocytes," Biochimica et Biophysica Acta, vol. 1052, no. 3, pp. 366-378, 1990.

[33] M. J. Benito, D. J. Veale, O. FitzGerald, W. B. van den Berg, and B. Bresnihan, "Synovial tissue inflammation in early and late osteoarthritis," Annals of the Rheumatic Diseases, vol. 64, no. 9, pp. 1263-1267, 2005.

[34] L. I. Sakkas, C. Scanzello, N. Johanson et al., "T cells and T-cell cytokine transcripts in the synovial membrane in patients with osteoarthritis," Clinical and Diagnostic Laboratory Immunology, vol. 5, no. 4, pp. 430-437, 1998.

[35] I. Saito, T. Koshino, K. Nakashima, M. Uesugi, and T. Saito, "Increased cellular infiltrate in inflammatory synovia of osteoarthritic knees," Osteoarthritis and Cartilage, vol. 10, no. 2, pp. 156-162, 2002.

[36] F. Pessler, L. X. Chen, L. Dai et al., "A histomorphometric analysis of synovial biopsies from individuals with Gulf War Veterans' Illness and joint pain compared to normal and osteoarthritis synovium," Clinical Rheumatology, vol. 27, no. 9, pp. 1127-1134, 2008.

[37] F. Eckstein, W. Wirth, and M. C. Nevitt, "Recent advances in osteoarthritis imaging - the Osteoarthritis Initiative," Nature Reviews Rheumatology, vol. 8, no. 10, pp. 622-630, 2012.

[38] C. Ding, Y. Zhang, and D. Hunter, "Use of imaging techniques to predict progression in osteoarthritis," Current Opinion in Rheumatology, vol. 25, no. 1, pp. 127-135, 2013.

[39] A. Guermazi, F. W. Roemer, D. Burstein, and D. Hayashi, "Why radiography should no longer be considered a surrogate outcome measure for longitudinal assessment of cartilage in knee osteoarthritis," Arthritis Research and Therapy, vol. 13, article 247, 2011.

[40] V. B. Kraus, "Waiting for action on the osteoarthritis front," Current Drug Targets, vol. 11, no. 5, pp. 518-520, 2010.

[41] F. W. Roemer, C. K. Kwoh, M. J. Hannon et al., "Risk factors for magnetic resonance imaging-detected patellofemoral and tibiofemoral cartilage loss during a six-month period: the Joints on Glucosamine study," Arthritis and Rheumatism, vol. 64, no. 6, pp. 1888-1898, 2012.

[42] S. K. Tanamas, A. E. Wluka, J.-P. Pelletier et al., "Bone marrow lesions in people with knee osteoarthritis predict progression of disease and joint replacement: a longitudinal study," Rheumatology, vol. 49, no. 12, pp. 2413-2419, 2010.

[43] C. K. Kwoh, "Osteoarthritis: clinical relevance of bone marrow lesions in OA," Nature Reviews Rheumatology, vol. 9, no. 1, pp. $7-8,2013$.

[44] L. Sharma, J. S. Chmiel, O. Almagor et al., "Significance of preradiographic magnetic resonance imaging lesions in persons at increased risk of knee osteoarthritis," Arthritis \& Rheumatology, vol. 66, no. 7, pp. 1811-1819, 2014.

[45] F. W. Roemer, A. Guermazi, D. T. Felson et al., "Presence of MRI-detected joint effusion and synovitis increases the risk of cartilage loss in knees without osteoarthritis at 30-month follow-up: the MOST study," Annals of the Rheumatic Diseases, vol. 70, no. 10, pp. 1804-1809, 2011.

[46] J. Sokolove and C. M. Lepus, "Role of inflammation in the pathogenesis of osteoarthritis: latest findings and interpretations," Therapeutic Advances in Musculoskeletal Disease, vol. 5, no. 2, pp. 77-94, 2013.

[47] H.-J. Park, S. S. Kim, S.-Y. Lee et al., "A practical MRI grading system for osteoarthritis of the knee: association with KellgrenLawrence radiographic scores," European Journal of Radiology, vol. 82, no. 1, pp. 112-117, 2013.

[48] H. J. Braun and G. E. Gold, "Diagnosis of osteoarthritis: imaging," Bone, vol. 51, no. 2, pp. 278-288, 2012.

[49] H. Nakamura, K. Masuko, K. Yudoh et al., "Positron emission tomography with ${ }^{18} \mathrm{~F}-\mathrm{FDG}$ in osteoarthritic knee," Osteoarthritis and Cartilage, vol. 15, no. 6, pp. 673-681, 2007.

[50] C. Y. J. Wenham and P. G. Conaghan, "New horizons in osteoarthritis," Age and Ageing, vol. 42, no. 3, pp. 272-278, 2013. 
[51] Y. Zhang, B. Kundu, K. D. Fairchild et al., "Synthesis of novel neutrophil-specific imaging agents for Positron Emission Tomography (PET) imaging," Bioorganic and Medicinal Chemistry Letters, vol. 17, no. 24, pp. 6876-6878, 2007.

[52] L. W. Locke, M. D. Chordia, Y. Zhang et al., "A novel neutrophilspecific PET imaging agent: cFLFLFK-PEG- ${ }^{64} \mathrm{Cu}$," The Journal of Nuclear Medicine, vol. 50, no. 5, pp. 790-797, 2009.

[53] L. Xiao, Y. Zhang, Z. Liu, M. Yang, L. Pu, and D. Pan, "Synthesis of the Cyanine 7 labeled neutrophil-specific agents for noninvasive near infrared fluorescence imaging," Bioorganic and Medicinal Chemistry Letters, vol. 20, no. 12, pp. 3515-3517, 2010.

[54] Y. Zhang, L. Xiao, M. D. Chordia et al., "Neutrophil targeting heterobivalent SPECT imaging probe: CFLFLF-PEG-TKPPR${ }^{99 \mathrm{~m}}$ Tc," Bioconjugate Chemistry, vol. 21, no. 10, pp. 1788-1793, 2010.

[55] L. Xiao, Y. Zhang, S. S. Berr et al., "A novel near-infrared fluorescence imaging probe for in vivo neutrophil tracking," Molecular Imaging, vol. 11, no. 5, pp. 372-382, 2012.

[56] S. Massey, K. Johnston, T. M. Mott et al., "In vivo bio luminescence imaging of Burkholderia mallei respiratory infection and treatment in the mouse model," Frontiers in Microbiology, vol. 2, article 174, 2011.

[57] G. J. Stasiuk, H. Smith, M. Wylezinska-Arridge et al., "Gd ${ }^{3+}$ cFLFLFK conjugate for MRI: a targeted contrast agent for FPR1 in inflammation," Chemical Communications, vol. 49, no. 6, pp. 564-566, 2013.

[58] J. Zhou, Y.-T. Tsai, H. Weng et al., "Real-time detection of implant-associated neutrophil responses using a formyl peptide receptor-targeting NIR nanoprobe," International Journal of Nanomedicine, vol. 7, pp. 2057-2068, 2012.

[59] D. A. Dorward, C. D. Lucas, A. G. Rossi, C. Haslett, and K. Dhaliwal, "Imaging inflammation: molecular strategies to visualize key components of the inflammatory cascade, from initiation to resolution," Pharmacology and Therapeutics, vol. 135, no. 2, pp. 182-199, 2012.

[60] S. E. VanCompernolle, K. L. Clark, K. A. Rummel, and S. C. Todd, "Expression and function of formyl peptide receptors on human fibroblast cells," The Journal of Immunology, vol. 171, no. 4, pp. 2050-2056, 2003.

[61] A. Viswanathan, R. G. Painter, N. A. Lanson Jr., and G. Wang, "Functional expression of $N$-formyl peptide receptors in human bone marrow-derived mesenchymal stem cells," Stem Cells, vol. 25, no. 5, pp. 1263-1269, 2007.

[62] W. Kao, R. Gu, Y. Jia et al., "A formyl peptide receptor agonist suppresses inflammation and bone damage in arthritis," British Journal of Pharmacology, vol. 171, no. 17, pp. 4087-4096, 2014.

[63] F. P. J. G. Lafeber and W. E. van Spil, "Osteoarthritis year 2013 in review: biomarkers; reflecting before moving forward, one step at a time," Osteoarthritis and Cartilage, vol. 21, no. 10, pp. 14521464, 2013.

[64] M. Attur, S. Krasnokutsky-Samuels, J. Samuels, and S. B. Abramson, "Prognostic biomarkers in osteoarthritis," Current Opinion in Rheumatology, vol. 25, no. 1, pp. 136-144, 2013.

[65] L. I. Sakkas, G. Koussidis, E. Avgerinos, J. Gaughan, and C. D. Platsoucas, "Decreased expression of the CD3 $\zeta$ chain in $\mathrm{T}$ cells infiltrating the synovial membrane of patients with osteoarthritis," Clinical and Diagnostic Laboratory Immunology, vol. 11, no. 1, pp. 195-202, 2004.

[66] C. R. Scanzello, E. Umoh, F. Pessler et al., "Local cytokine profiles in knee osteoarthritis: elevated synovial fluid interleukin-15 differentiates early from end-stage disease," Osteoarthritis and Cartilage, vol. 17, no. 8, pp. 1040-1048, 2009.

[67] S. Khalifé and M. Zafarullah, "Molecular targets of natural health products in arthritis," Arthritis Research \& Therapy, vol. 13, article 102, 2011.

[68] S. Kyrkanides, R. H. Tallents, J.-N. H. Miller et al., "Osteoarthritis accelerates and exacerbates Alzheimer's disease pathology in mice," Journal of Neuroinflammation, vol. 8, article 112, 2011.

[69] C. L. Hill, D. J. Hunter, J. Niu et al., "Synovitis detected on magnetic resonance imaging and its relation to pain and cartilage loss in knee osteoarthritis," Annals of the Rheumatic Diseases, vol. 66, no. 12, pp. 1599-1603, 2007.

[70] M. L. Schenker, R. L. Mauck, and S. Mehta, "Pathogenesis and prevention of posttraumatic osteoarthritis after intra-articular fracture," Journal of the American Academy of Orthopaedic Surgeons, vol. 22, no. 1, pp. 20-28, 2014.

[71] R. F. Loeser, "Osteoarthritis year in review 2013: biology," Osteoarthritis and Cartilage, vol. 21, no. 10, pp. 1436-1442, 2013.

[72] E. F. Goljan, Rapid Review Pathology, Elsevier/Saunders, Philadelphia, Pa, USA, 4th edition, 2014.

[73] X. Chevalier, T. Conrozier, and P. Richette, "Desperately looking for the right target in osteoarthritis: the anti-IL-1 strategy," Arthritis Research and Therapy, vol. 13, article 124, 2011.

[74] M. Z. C. Ruan, A. Erez, K. Guse et al., "Proteoglycan 4 expression protects against the development of osteoarthritis," Science Translational Medicine, vol. 5, no. 176, Article ID 176ra34, 2013.

[75] J. A. Martin, D. McCabe, M. Walter, J. A. Buckwalter, and T. O. McKinley, " $N$-acetylcysteine inhibits post-impact chondrocyte death in osteochondral explants," The Journal of Bone and Joint Surgery A, vol. 91, no. 8, pp. 1890-1897, 2009.

[76] P. L. E. M. Van Lent, A. B. Blom, P. Van Der Kraan et al., "Crucial role of synovial lining macrophages in the promotion of transforming growth factor $\beta$-mediated osteophyte formation," Arthritis and Rheumatism, vol. 50, no. 1, pp. 103-111, 2004.

[77] H. Nakamura, S. Yoshino, T. Kato, J. Tsuruha, and K. Nishioka, "T-cell mediated inflammatory pathway in osteoarthritis," Osteoarthritis and Cartilage, vol. 7, no. 4, pp. 401-402, 1999.

[78] A. Guerassimov, Y. Zhang, A. Cartman et al., "Immune responses to cartilage link protein and the G1 domain of proteoglycan aggrecan in patients with osteoarthritis," Arthritis \& Rheumatism, vol. 42, no. 3, pp. 527-533, 1999.

[79] H. de Jong, S. E. Berlo, P. Hombrink et al., "Cartilage proteoglycan aggrecan epitopes induce proinflammatory autoreactive T-cell responses in rheumatoid arthritis and osteoarthritis," Annals of the Rheumatic Diseases, vol. 69, no. 1, pp. 255-262, 2010.

[80] R.-R. Da, Y. Qin, D. Baeten, and Y. Zhang, "B cell clonal expansion and somatic hypermutation of Ig variable heavy chain genes in the synovial membrane of patients with osteoarthritis," The Journal of Immunology, vol. 178, no. 1, pp. 557-565, 2007.

[81] S. Shiokawa, N. Matsumoto, and J. Nishimura, "Clonal analysis of B cells in the osteoarthritis synovium," Annals of the Rheumatic Diseases, vol. 60, no. 8, pp. 802-805, 2001.

[82] J. Mollenhauer, K. von der Mark, G. Burmester, K. Gluckert, E. Lutjen-Drecoll, and K. Brune, "Serum antibodies against chondrocyte cell surface proteins in osteoarthritis and rheumatoid arthritis," The Journal of Rheumatology, vol. 15, no. 12, pp. 1811$1817,1988$.

[83] F. Doss, J. Menard, M. Hauschild et al., "Elevated IL-6 levels in the synovial fluid of osteoarthritis patients stem from plasma cells," Scandinavian Journal of Rheumatology, vol. 36, no. 2, pp. 136-139, 2007. 
[84] M. D. Smith, S. Triantafillou, A. Parker, P. P. Youssef, and M. Coleman, "Synovial membrane inflammation and cytokine production in patients with early osteoarthritis," The Journal of Rheumatology, vol. 24, no. 2, pp. 365-371, 1997.

[85] M. Kobayashi, G. R. Squires, A. Mousa et al., "Role of interleukin-1 and tumor necrosis factor $\alpha$ in matrix degradation of human osteoarthritic cartilage," Arthritis and Rheumatism, vol. 52, no. 1, pp. 128-135, 2005.

[86] Z. Fan, B. Bau, H. Yang, S. Soeder, and T. Aigner, "Freshly isolated osteoarthritic chondrocytes are catabolically more active than normal chondrocytes, but less responsive to catabolic stimulation with interleukin-1 $\beta$," Arthritis \& Rheumatism, vol. 52, no. 1, pp. 136-143, 2005.

[87] N. Akhtar and T. M. Haqqi, "Epigallocatechin-3-gallate suppresses the global interleukin-lbeta-induced inflammatory response in human chondrocytes," Arthritis Research and Therapy, vol. 13, no. 3, article R93, 2011.

[88] J. N. Gouze, K. Bordji, S. Gulberti et al., "Interleukin-1beta down-regulates the expression of glucuronosyltransferase I, a key enzyme priming glycosaminoglycan biosynthesis: influence of glucosamine on interleukin-lbeta-mediated effects in rat chondrocytes," Arthritis \& Rheumatism, vol. 44, no. 2, pp. 351$360,2001$.

[89] F. Heraud, A. Heraud, and M.-F. Harmand, "Apoptosis in normal and osteoarthritic human articular cartilage," Annals of the Rheumatic Diseases, vol. 59, no. 12, pp. 959-965, 2000.

[90] M. Mathy-Hartert, L. Hogge, C. Sanchez, G. Deby-Dupont, J. M. Crielaard, and Y. Henrotin, "Interleukin- $1 \beta$ and interleukin6 disturb the antioxidant enzyme system in bovine chondrocytes: a possible explanation for oxidative stress generation," Osteoarthritis and Cartilage, vol. 16, no. 7, pp. 756-763, 2008.

[91] J.-P. Pelletier, F. Mineau, P. Ranger, G. Tardif, and J. MartelPelletier, "The increased synthesis of inducible nitric oxide inhibits IL-1ra synthesis by human articular chondrocytes: possible role in osteoarthritic cartilage degradation," Osteoarthritis and Cartilage, vol. 4, no. 1, pp. 77-84, 1996.

[92] X. Li, M. Ellman, P. Muddasani et al., "Prostaglandin $E_{2}$ and its cognate EP receptors control human adult articular cartilage homeostasis and are linked to the pathophysiology of osteoarthritis," Arthritis \& Rheumatism, vol. 60, no. 2, pp. 513$523,2009$.

[93] P.-A. Guerne, B. L. Zuraw, J. H. Vaughan, D. A. Carson, and M. Lotz, "Synovium as a source of interleukin 6 in vitro. Contribution to local and systemic manifestations of arthritis," The Journal of Clinical Investigation, vol. 83, no. 2, pp. 585-592, 1989.

[94] F. Legendre, J. Dudhia, J.-P. Pujol, and P. Bogdanowicz, "JAK/ STAT but not ERK1/ERK2 pathway mediates interleukin (IL)6/soluble IL-6R down-regulation of type II collagen, aggrecan core, and link protein transcription in articular chondrocytes. Association with a down-regulation of Sox9 expression," The Journal of Biological Chemistry, vol. 278, no. 5, pp. 2903-2912, 2003.

[95] B. Porée, M. Kypriotou, C. Chadjichristos et al., "Interleukin-6 (IL-6) and/or soluble IL-6 receptor down-regulation of human type II collagen gene expression in articular chondrocytes requires a decrease of Sp1.Sp3 ratio and of the binding activity of both factors to the COL2A1 promoter," The Journal of Biological Chemistry, vol. 283, no. 8, pp. 4850-4865, 2008.

[96] T. E. Cawston, V. A. Curry, C. A. Summers et al., "The role of oncostatin $\mathrm{M}$ in animal and human connective tissue collagen turnover and its localization within the rheumatoid joint," Arthritis \& Rheumatology, vol. 41, pp. 1760-1771, 1998.

[97] J. Suurmond, A. L. Dorjee, M. R. Boon et al., "Mast cells are the main interleukin-17-positive cells in anti-citrullinated protein antibody-positive and -negative rheumatoid arthritis and osteoarthritis synovium," Arthritis Research \& Therapy, vol. 13, no. 5, article R150, 2011.

[98] T. L. Y. Brown, H. J. Spencer, K. E. Beenken et al., "Evaluation of dynamic $\left[{ }^{18} \mathrm{~F}\right]-\mathrm{FDG}-\mathrm{PET}$ imaging for the detection of acute post-surgical bone infection," PLOS ONE, vol. 7, no. 7, Article ID e41863, 2012.

[99] C. Wu, F. Li, G. Niu, and X. Chen, "PET imaging of inflammation biomarkers," Theranostics, vol. 3, no. 7, pp. 448-466, 2013.

[100] C. M. Griessinger, R. Kehlbach, D. Bukala et al., "In vivo tracking of thl cells by PET reveals quantitative and temporal distribution and specific homing in lymphatic tissue," The Journal of Nuclear Medicine, vol. 55, no. 2, pp. 301-307, 2014.

[101] L. Tran, A. D. R. Huitema, M. H. Van Rijswijk et al., "CD20 antigen imaging with ${ }^{124}$ I-rituximab PET/CT in patients with rheumatoid arthritis," Human Antibodies, vol. 20, no. 1-2, pp. 29-35, 2011.

[102] Q. Wang, X. Shi, X. Zhu, M. Ehlers, J. Wu, and C. Schmuck, "A fluorescent light-up probe as an inhibitor of intracellular $\beta$ tryptase," Chemical Communications, vol. 50, no. 46, pp. 61206122, 2014.

[103] Q. Cao, W. Cai, Z.-B. Li et al., "PET imaging of acute and chronic inflammation in living mice," European Journal of Nuclear Medicine and Molecular Imaging, vol. 34, no. 11, pp. 1832-1842, 2007.

[104] G. Girardi, J. Fraser, R. Lennen, R. Vontell, M. Jansen, and G. Hutchison, "Imaging of activated complement using ultrasmall superparamagnetic iron oxide particles (USPIO)_conjugated vectors: an in vivo in utero non-invasive method to predict placental insufficiency and abnormal fetal brain development," Molecular Psychiatry, 2014.

[105] D. Hartung, M. Schäfers, S. Fujimoto et al., "Targeting of matrix metalloproteinase activation for noninvasive detection of vulnerable atherosclerotic lesions," European Journal of Nuclear Medicine and Molecular Imaging, vol. 34, supplement 1, pp. S1S8, 2007. 


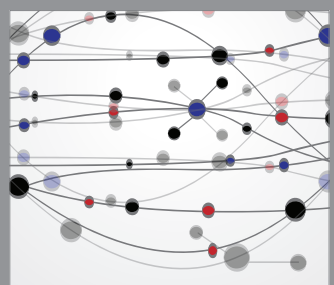

The Scientific World Journal
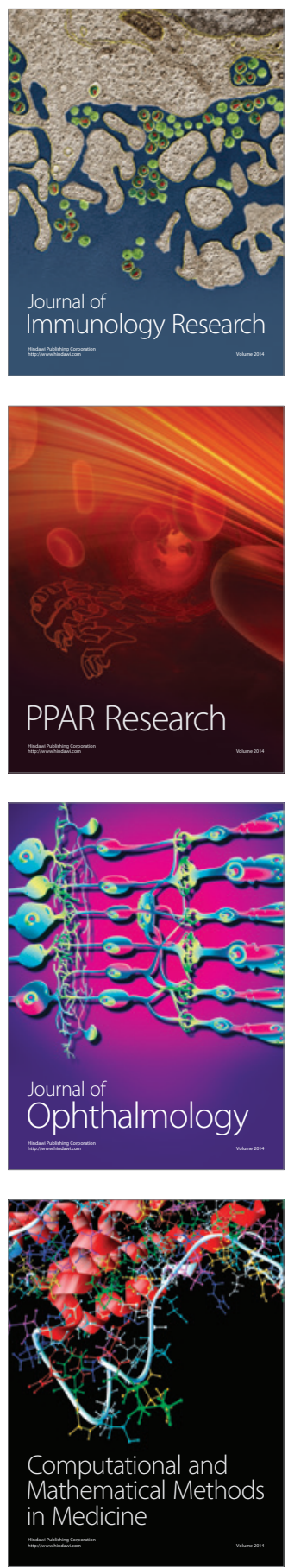

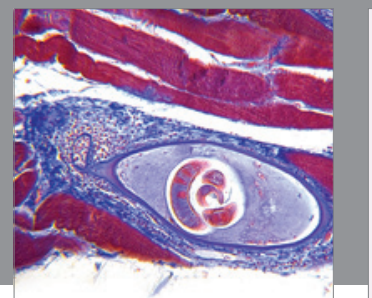

Gastroenterology

Research and Practice
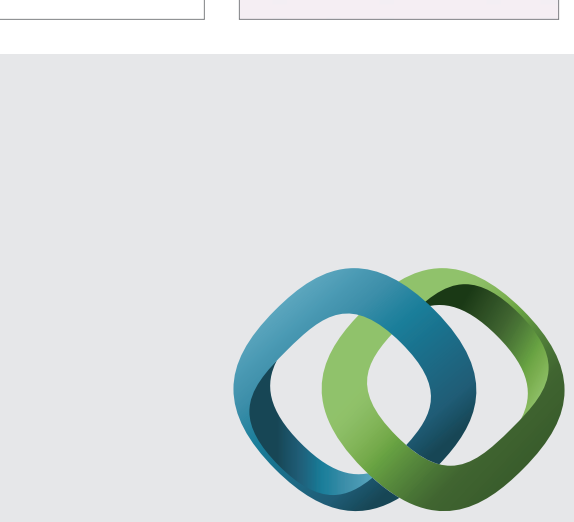

\section{Hindawi}

Submit your manuscripts at

http://www.hindawi.com
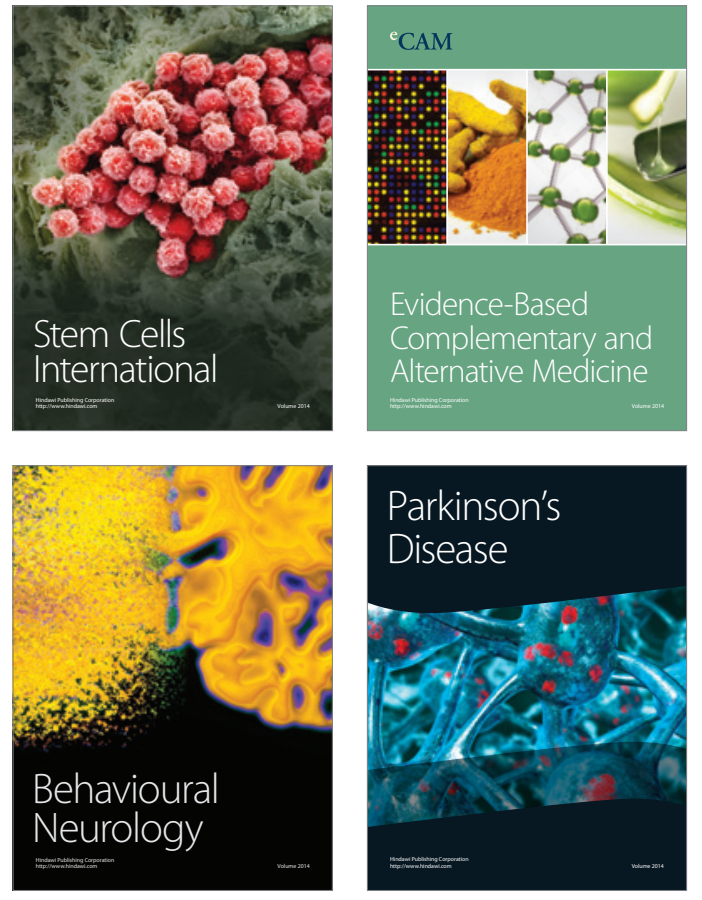
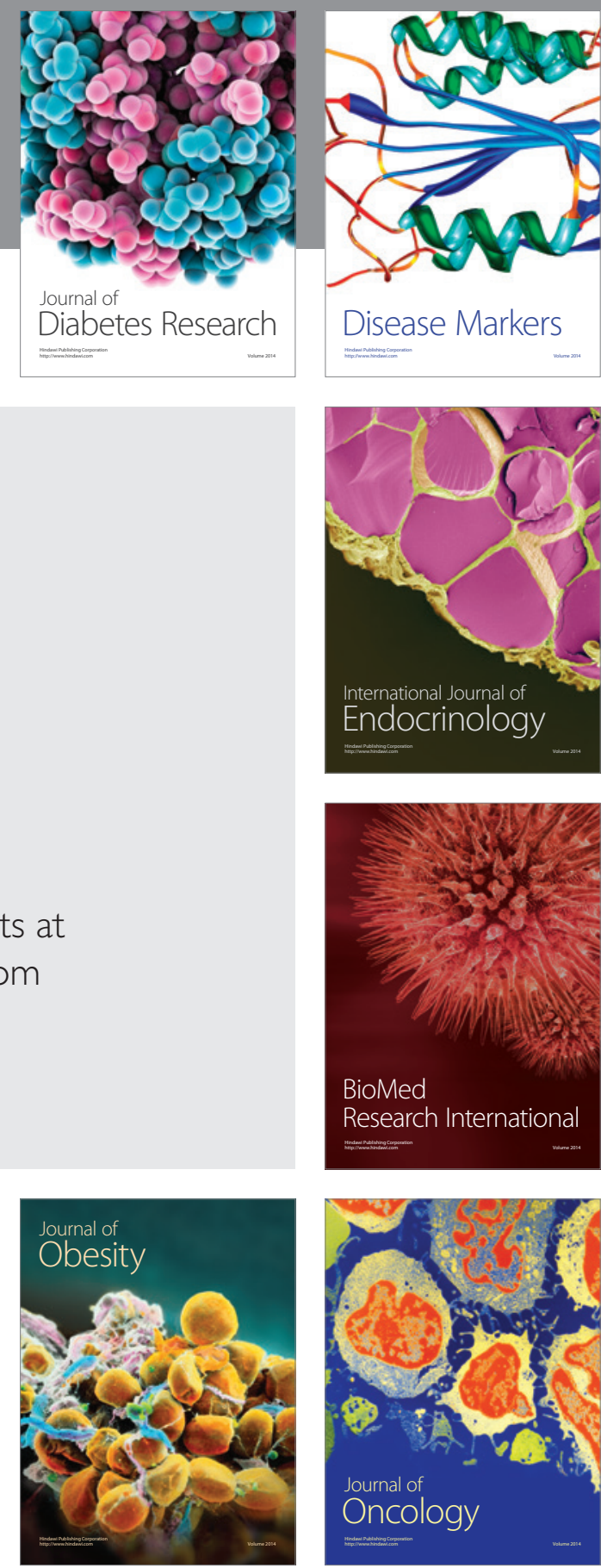

Disease Markers
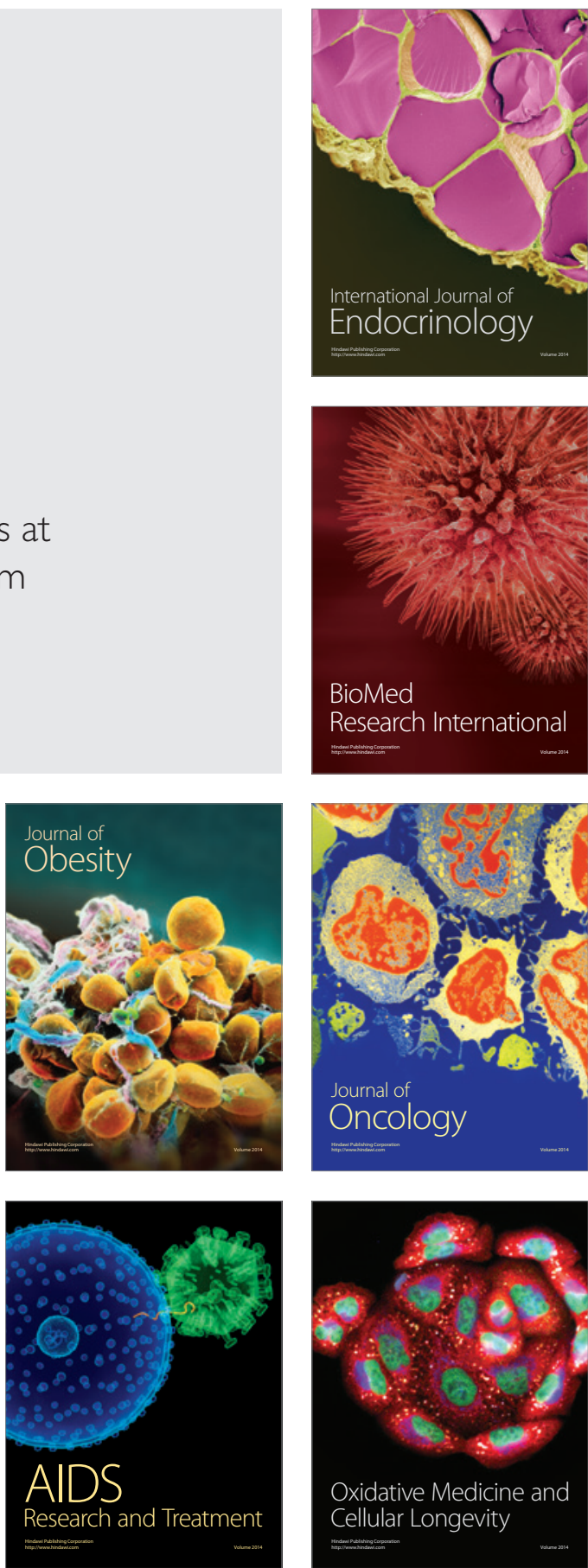